\title{
Sobre feitiços e ritos: enfermidade e cura nas reduções jesuítico-guaranis, século XVII
}

\section{On spells and rites: illness and cure in the Jesuit Guarany reductions in the XVII century}

\section{Eliane Cristina Deckmann Fleck}

\author{
"[...] con anterioridad a la labor misionera entre los \\ Guaranies, y antes de la venida de los españoles, estos indios \\ eran sanisimos, y como se expresaba un misionero al referirse a \\ ellos, sólo conocían una enfermedad: la vejez"'
}

Esta observação de Furlong nos remete a algumas indagaçōes: Como os indígenas mantinham-se sãos? Como curavam suas enfermidades? De acordo com este mesmo autor, os índios guarani tinham seus médicos e seus medicamentos, extraídos de sementes, raízes e folhas de árvores, praticando escarificações, cauterizações, aplicação de ungüentos e ventosas e tratamentos para verminoses. ${ }^{2}$

A manutenção dessas práticas terapêuticas entre os Guarani, em especial, do uso de ervas, raízes, resinas e gorduras animais, fica evidenciada na lista de enfermidades e seu respectivo tratamento organizada por Cadogan e que contempla desde a dor de ouvido, até a epilepsia e os métodos contraceptivos. ${ }^{3}$ Ele registra, ainda, o uso do "humo de tabaco" que "ahuyenta tanto los seres malignos como los pesares y las enfermedades, empleándose en la medicina y los ritos" . ${ }^{4} \mathrm{Faz}$, ainda, referência às plantas milagrosas que "podrán ser halladas y utilizadas por quienes se dedican con fervor a los ejercicios espirituales y adquieren la buena ciencia; es decir, los médicos agoreros"5.

Interessante observar que Furlong atribui a incidência de males gastrointestinais entre os Guarani às alteraçôes em sua dieta alimentar, com a 
introdução, pelos missionários, do consumo de carne bovina. ${ }^{6}$ Entre as doenças mais graves que se tornaram freqüentes entre os Guarani, ao longo do século 17 , ele destaca a varíola, observando que "Parece cierto que los españoles importaron este mal, que en forma tan rápida diezmaba a los indígenas que vivían en comunidad". 7 Segundo este mesmo autor, apesar da disponibilidade de uma farmacopéia rica, as pestes que os missionários jesuítas registraram em suas Cartas Ânuas não puderam ser evitadas e nem eficazmente combatidas, por estarem os indígenas desprovidos de anticorpos para delas se defenderem. ${ }^{8}$ Ao se referirem às pestes que acometeram os Guarani, há unanimidade entre os autores em estabelecer sua vinculação com a implantação das reduções.

La concentración de varios millares de indios en una sola aldea revoluciona de tal manera la economía tradicional [...] Al debilitar a los indios, esta hambre favorece la propagación de enfermedades importadas, contra las cuales su organismo no tiene defensa. Más o menos violentas, más o menos fulminantes, siempre, al decir de los propios jesuítas, las epidemias causan estragos entre las nacientes cristiandades; y la concentración de los catecúmenos no hace sino favorecer la hecatombe. ${ }^{9}$

É importante observar que apesar de os jesuítas terem se dedicado ao alívio dos doentes, as Constituiçôes da Ordem definem "las ocupaciones que no convienen a clérigos y religiosos y entre ellas se cuenta la medicina, y mucho más el comercio al parecer íntimamente ligado al sostén de boticas”. ${ }^{10}$ Estas proibições podiam ser, no entanto, desconsideradas, quando o atendimento se fazia necessário, "tratándose de la misericordia y caridad para con los pobres, cuando hace falta otro médico o cirujano"11. A freqüência dos atendimentos levaria o Papa Gregório XIII, em 1576, a outorgar à Companhia de Jesus permissão para a prática da medicina, nos seguintes termos:

Ya que consta por la experiencia, que los fieles se inclinan mucho a la religión y piedad, si las personas religiosas ejercen para con ellos los oficios de la caridad, no sólo con sus almas, sino también con sus cuerpos, y habviendo la Compañía de Jesús, según supimos, algunos religiosos entendidos en medicina, cuya asistencia ante todo en regiones donde faltan médicos, puede ser muy útil no sólo para las almas, sino también 
para los cuerpos, contribuyendo este oficio de caridad no poco a la edificación y a la gloria de Dios: para habilitar a semejantes religiosos a esta práctica, sin que incurran en censuras, ni se inquieten en su conciencia [...] damos este presente indulto con autoridad apostólica [...] a todos y a cada uno de la referida Compañía de Jesús, entendidos en medicina, que hay ahora o que hubiere en adelante, para que, con el permiso de sus superiores libre y lícitamente curen [...] tanto a los enfermos de la misma Religión, como a extraños y seglares con tal que no se trate de adistión o incisión hecha por ellos en persona; y en el caso de que no pueda comodamente acudir a los médicos seglares[... $]^{12}$

Durante os séculos XVI e XVII e, ainda na primeira metade do século XVIII, os Jesuítas puderam exercer a medicina "y expender a la gente las necesarias medicinas", face à não existência dos chamados "Protomedicatos" implantados nos diversos Vice-Reinos somente após a primeira metade do século XVIII. A referida falta de médicos é atestada pela solicitação, feita em 1642, pelo Cabildo de Buenos Aires à cidade de Córdoba, na qual fica expresso que face a "los frecuentes apuros de peste" se fazia necessária a vinda de um médico, já que "no hay médico ni medicinas"13.

O sétimo artigo da $1^{\text {a }}$ Instrução do $P^{e}$. Diego de Torres Bollo (1609), que deixa claras as condições a serem observadas pelos jesuítas no momento da instalação da redução, expressa a preocupação com o controle de doenças e com o eficiente abastecimento de alimentos. Neste sentido, além de estarem autorizados a atuar como médicos nas situaçóes de epidemias, deveriam, através de medidas de prevenção, evitar a debilitação dos indígenas pela fome ou pela instalação de determinadas enfermidades.

No sítio mais apto façam a Redução e a povoação [...] Nisso advertirão primeiro que tenha água, pescaria, boas terras e que estas não sejam todas alagadiças, nem muito quentes, mas que tenham bom clima e se apresentem sem mosquitos e isentas de outros incômodos $[\ldots]^{14}$

Ressaltamos que, nos séculos 16 e 17, os médicos formados nas universidades recebiam um ensino puramente acadêmico sobre os princípios de fisiologia dos humores. Aprendiam que a doença surgia de um desequilíbrio entre os quatro humores (o sangue, a fleuma, a bílis amarela e a bílis negra). O diagnóstico consistia em estabelecer qual humor estava desequilibrado, e a terapia, em medidas para recompor o equilíbrio, fosse por san- 
grias $^{15}$ - com cortes na veia, escarificação ou aplicação de sanguessugas - ou pela submissão do paciente a uma série de purgantes e vomitórios. Assim, o médico seguia uma monótona rotina de sangrias e purgas, prescrevendo ainda emplastros, ungüentos e poções. ${ }^{16}$ A Décima-Quarta Carta Ânua, relativa aos anos de 1635 a 1637, refere a prática:

Esta peste postró en menos de ocho días a toda la población, a grandes y chicos, hombres y mujeres. Sólo yo y un joven quedamos en pie [...] Adonde me volvía, no veía yo sino oscuras llagas, apostemas destilando pus y gusanos, y en todas partes se me presentaba el retrato de la muerte. Y para cuidar a cuatro mil enfermos quedaba sólo yo com aquel joven. Aconsejáronme algunas personas, sería bueno sangrar a los dolientes, y por no haber outro cirujano, yo en persona comencé a ejercer este oficio desconocido, abriendo venas día y noche. ${ }^{17}$

Bastante oportunas são as considerações de M. Haubert que a partir dos efeitos provocados pelas epidemias, pergunta: “¿Cómo no escuchar entonces, com espíritu predispuesto, a sus grandes magos que les predican que sus males provienen de haber seguido a los sacerdotes extranjeros, y que, al hacerlos desaparecer, recuperarían la felicidad de sus antepasados?" 18 . É importante lembrar que os próprios missionários reconheciam que "las epidemias causan estragos en las nacientes cristiandades", visto que em razão delas, os índios buscavam novamente a proteção dos xamãs.

O fato é que conquistadores e missionários introduziram vírus e bactérias para os quais as populações nativas não possuíam anticorpos, o que provocou as epidemias e o descenso populacional. ${ }^{19} \mathrm{~A}$ introdução e a propagação de doenças desconhecidas como a gripe, sarampo, varíola, tuberculose, disenteria, febre amarela, malária, pneumonia epidêmica, cólera, tifo, sífilis, lepra, doenças venéreas, podem ser percebidas como o "hálito da Morte" ${ }^{20}$ que debilitou e desorganizou as populaçōes atingidas, facilitando o avanço da frente espanhola, porque "esas pestes desconocidas e incontrolables tenían que producir, además de su hundimiento demográfico, la más total desmoralización del indio". ${ }^{21}$

Em seu estudo sobre a epidemiologia na Amazônia, Coimbra Jr. afirma que "após o contato com sociedades de cultura ocidental é comum observarem-se drásticas mudanças em diferentes aspectos da vida destas populações". Dentre elas, destaca a "acentuada mortalidade verificada entre 
sociedades indígenas que quase sempre marca o período pós-contato" e o "processo de sedentarização, observando-se acentuada diminuição da mobilidade, aliada a mudanças no padrão de distribuição espacial das aldeias, organização social e sistema de subsistência”. Todas estas alterações, observa o autor, "têm implicações epidemiológicas [...]" 22.

Cabe lembrar também que os surtos epidêmicos provocaram a desestruturação e a desterritorialização tribal que levou à desnutrição, ou ainda às mudanças de dieta que, por sua vez, produziram novos distúrbios de saúde devido à fome ou à introdução de novos alimentos.

Como bem salientou Carlos Coimbra Jr., "o mesmo processo saúde/ doença caracteriza uma das facetas de um sistema maior, onde indivíduos interagem com diferentes fatores ambientais em sua rotina diária de subsistência". Dessa forma, "o quadro epidemiológico de uma população pode ser visualizado como resultante da constante interação entre uma gama de fatores de ordem biológica, ambiental e sócio-cultural" ${ }^{23}$.

Considerando o imenso território que os Guarani ocupavam no século $\mathrm{XVI}^{24}$, as epidemias eram facilmente propagáveis, devido a sua grande população e à intensa comunicação que existia entre as aldeias, ligadas por uma rede de trilhas e caminhos abertos no interior das florestas ou pelos cursos d'água.

Observamos este aspecto na Carta Ânua de 1634, na qual o Pe. Romero atribui a propagação das epidemias ao fato de os Guarani serem "naturalmente andarilhos", o que provocava o descenso populacional, já que poucos "escapavam de padeçer destas pestes e enfermidades e, assim, uns sucessivamente a outros vão caindo" 25 . Em outro momento, o Pe. Romero refere a inexistência de cura para os infectados:

[...] o maior trabalho que temos nestas pestes e o que mais desassossego nos traz é o cuidar dos que estão fora da redução, porque muitas vezes vendo que pica a epidemia na redução, vão para suas antigas aldeias para que ela não os ataque, pensando estarem muito seguros lá. Outros, logo que começam a ficar enfermos, também se vão para curar-se lá, como eles dizem (como se tivessem os tristes alguma medicina ou médico que lhes curassem). Outros fogem da redução para que os padres não lhes curem nem lhes tirem as comidas. ${ }^{26}$ 
$\mathrm{O}$ mesmo Pe. Romero nos oferece a sua interpretação com relação às possíveis causas e natureza das epidemias, deixando entrever a concepção galênica de doença:

[...] é coisa muito particular e notável de muitos anos atrás, que começando alguma peste em alguma destas reduções, pouco a pouco vai correndo pelas demais, e é coisa muito rara e particular providência de $\mathrm{N}$. Sr. o milagre patente que ocorre se algum se livra dela. E isto se pode atribuir ao fato de que têm quase todos as mesmas complexões, as mesmas comidas, e guardar todos ou uma, sem discrepar um mesmo teor de vida, e assim as enfermidades nascidas destes humores e destemperanças de comidas etc. são as mesmas em todos. ${ }^{27}$

Nessa mesma carta se faz referência à forma como os missionários contornavam a falta de pessoal para o atendimento dos doentes e que pode ter causado a disseminação das epidemias: "[...] muitas vezes enviamos às aldeias antigas dos índios um mancebo enfermo". ${ }^{28}$

As doenças trazidas pelos espanhóis colocaram, portanto, os Guarani frente a uma necessária reformulação de suas atitudes diante da doença e da morte. Isso pode ser observado tanto no "Tesoro de la Lengua Guarani”, quanto no "Bocabulário de la Lengua Guarani"29, organizados pelo Pe. Antônio Ruiz de Montoya e que registram, entre outras, as expressões ligadas às doenças, às epidemias e às reaçōes dos Guarani frente a suas desastrosas conseqüências. Mais do que dicionários, estas obras contêm a sistematização de elementos etnográficos da cultura guarani, constituindo-se na maior suma etnológica guarani já coletada. Daí a importância dos verbetes selecionados e traduzidos pelo Pe. Montoya para uma análise da reformulação de suas atitudes e práticas.

As epidemias, então definidas como "peste" ou "enfermedad" pelos jesuítas, foram denominadas pelos Guarani como mbaba, taçi ai, maraa, mbae açi. ${ }^{30}$ Entre as doenças epidêmicas referidas: tepotí ugui ou tepoti pyta = "câmaras de sangre/desinteria"; mbirua = "ampollas/sarampo"; acanundu yrundi ara - naboguara = "quartãns/malária”. Como expressóes reveladoras da percepção e dos efeitos das epidemias destacamos: nache mo amongueri taci = "a enfermidade levou minha gente"; chembotiabo mbar raci $=$ "a enfermidade acabou com a minha gente"; $y$ pichibi tabaa oupa 
hacipabamo = "está a aldeia espantada com tantos enfermos"; mbae aci oqui rucu ore rehe = "chove a enfermidade sobre nós".

Retomando a abordagem de Coimbra Jr. em relação às diferentes respostas das sociedades indígenas frente às epidemias, destacamos "a dispersão e fuga dos membros da aldeia, a aglomeração de seus habitantes em uma mesma maloca e a interrupção voluntária de atividade de subsistência" ${ }^{11}$ como os padrôes de comportamento mais comumente observados e acionados a partir de seu sistema de crenças e práticas médicas tradicionais.

Há que considerar, para uma aproximação, que os indígenas americanos "mantenían un equilibrio sanitario entre las causas de enfermedad y su medio ambiente"; acreditavam "en el origen mágico y sobrenatural de la enfermedad” e apoiavam suas práticas médicas "en recursos mágicos y religiosos y en alguna medida en remedios vegetales". Para eles, a enfermidade era "el resultado de fuerzas extrañas y superiores al hombre, frente a las que solamente cabía el recurso a ofrendas y desagravios de tipo individual o colectivo, según la naturaleza del pecado cometido"32. Quanto às tendências predominantes na vivência religiosa dos indígenas sul-americanos, Susnik observou que "El hombre es consciente que todo o existente establecido puede reaccionar a él, cuando ocurren transgreciones del equilibrio de la vivencia; pueden irritarse las deidades, los dueños de animales y naturaleza o ya las almas des-idas de los muertos, infligiendo los 'castigos' de acuerdo a las violaciones sociomorales” (Susnik, 1989, p. 95).

Entre os Guarani e os povos primitivos em geral, "enfermedad significa estar poseído o dominado por espiritus animales telúricos, que roban o destruyen al individuo, su alma, o su órgano enfermo" e aquele que revelarse "dueño del remedio" ou "controlador de los espíritus malignos" demonstrará o verdadeiro poder mágico e religioso ${ }^{33}$. Para estes indígenas, as enfermidades tinham um caráter mágico, uma vez que se deviam à intrusão de um corpo estranho no organismo ou então a um malefício enviado por um inimigo. ${ }^{34}$

Para ilustrar este aspecto, destacamos uma referência de Cadogan à punição pelos deuses decorrente da quebra de um tabu:

Cuando uno de los cónyuges hja sido culpable de adulterio hallándose la madre embarazada, los dioses se niegan a darle nombre a la criatura; 
es decir, se niegan a dotarle de "aquello que sostendrá erguido el fluir de su decir" = o mbo-e-ry moäá; y la criatura está condenada a morir prematuramente. ${ }^{35}$

Essa mesma relação entre infrações do código moral e enfermidade pode ser percebida nesta interpretação dada ao que ocorreu com um indígena e que vincula a punição à desobediência às regras:

Pa’i Jachy enseñaron a los hombres la danza, las oraciones y los himnos sagrados. Un día en que Pa’i había ordenado fuera dedicado a la danza y la oración, un indio desobediente se internó en la selva en busca de hojas de pindó (palmera) para techar un rancho. Al volver fué convertido en oso hormiguero grande $[\ldots]^{36}$

Na visão européia seiscentista, "o mal é [...] considerado como uma realidade material, trazido de fora ('o Inferno') pelos 'demônios' e colocado no corpo do doente, o qual se encontrava exposto, sem defesa, a semelhante perigo pelo seu deus, a quem ofendera e que o abandonava assim aos executores da sua vingança” (Le Goff, 1990, p. 23). Isso poderia explicar a difusão e a consagração dessa percepção nas reduçóes, na medida em que tanto para os europeus, quanto para os Guarani, a perturbação da ordem natural - por intervenções sobrenaturais - decorria de transgressão moral ou religiosa. Apesar dessa percepção em comum, os missionários condenaram o emprego de ervas, resinas e bálsamos indígenas, limitando-se aos remédios europeus e às práticas terapêuticas européias, o que prejudicou o alívio dos enfermos em doenças que não puderam ser evitadas e para as quais não havia cura.

O missionário jesuíta António Ruiz de Montoya registrou o amplo e difundido uso de ervas medicinais nas práticas curativas dos Guarani:

Usam os índios muitos remédios e ervas (medicinais), que lá a natureza tem produzido. A pedra de São Paulo é de ajuda comprovada; são-no também os alhos esmagados ingeridos o remédio como bebida, a pedra bezoar e outras ervas (medicinais). Mas, mais caseiro é o fogo, queimando-se com uma faca em brasa a parte ferida pulverizada com enxofre. É conhecido este remédio e, acudindo-se a tempo, gente picada por tais cobras está fora de perigo. Os fígados da víbora, sendo ingeridos com alimento, usam-nos como remédio. ${ }^{37}$ 
Atribuiu, no entanto, um caráter supersticioso à atuação do xamã, pois no seu entendimento:

As superstições dos feiticeiros baseiam-se em adivinhações por meio dos cantos das aves: do que inventaram a não poucas fábulas relativas a medicar e isto com embustes, chupando, por exemplo, ao enfermo, as partes lesadas e tirando o feiticeiro da boca objetos que nela leva ocultos ou escondidos, e mostrando que ele, com sua virtude, lhe tinha tirado aquilo que lhe causava a doença, assim como uma espinha de peixe, um carvão ou coisa semelhante. ${ }^{38}$

A crença de que as doenças eram provocadas por feiticeiros "enterradores" 39 foi registrada pelo Pe. Montoya:

Os piores e mais perniciosos vêm a ser os 'enterradores' cujo ofício é matar, enterrando eles, na casa de quem se deseja matar, algumas sobras de sua comida, cascas de fruta e pedaços de carvão etc. Às vezes enterram sapos atravessados com alguma espinha de peixe: com o que se vai enfraquecendo aquele que querem matar, e este, sem outro acidente, morre. ${ }^{40}$

Outro aspecto fundamental da atitude dos missionários frente às doenças está relacionado com a prática da magia curativa, de uma "medicina de tipo exorcista". Em relação a estas curas, é pertinente observar que "o controle proporcionado por tais ritos mágicos é necessariamente ilusório" " ${ }^{11}$, pois os amuletos, os encantamentos e a água benta "não possuem qualquer virtude sobrenatural intrínseca" ${ }^{42}$. Apesar de "a magia em si ser vã, ela tem, no entanto, preciosos efeitos colaterais" ${ }^{43}$, diminuindo a ansiedade e predispondo o doente à cura pela imaginação e pela fé.

Este aspecto fica evidenciado na análise que fizemos das Cartas Ânuas da Província Jesuítica do Paraguai, do período que se estende de 1610 a 1643, e que apontam para o emprego de terapêutica mágica através do uso de relíquias, do batismo, da extrema-unção, do viático, do licor de São Nicolau, das imagens de santos e da água benta. Empregada em doenças que abrangem, desde picadas de cobras, dores musculares, disenteria, inchaço nos olhos, gripe e garganta inchada, peito inchado, febres, até reumatismo, surdez, hemorragias, coqueluche, lepra, varíola, sarampo e câncer, esta terapêutica está associada, invariavelmente, à cura ou à não-cura, ambas mani- 
puladas pelos missionários com a intenção de converter os indígenas, acenando-lhes com a promessa da vida eterna. Isto pode ser comprovado em registros nos quais a ênfase dada nos relatos é a cura por intercessão divina ou pelo uso de relíquias sagradas, como nesta Carta de 1626:

Un niño estaba muy enfermo vino su Pe. a rogarme que le aplicase una reliquia de Nro. Pe. S. Ignacio, que es mucho que en tan breve tiempo le conozcan, confiando de alcanzar salud para el hijo por medio de su intercessión; hiçose asi i cobrola el niño. ${ }^{44}$

A resistência anteriormente referida pode ser observada, inclusive, no tratamento das enfermidades dos missionários, como fica claro na Informação sobre a Redução de Nra. Sra. De la Natividad del Acarayg:

Yo avia mas de mes i medio que lo estaba de tiriçia [...] e el Pe. Claudio com su gran caridad hiço una chozuela com unos cueros [...] i alli cobre alguna mejoria, mas con las oraziones / las oraziones del Pe. que con otro remedio, que no le avia, ni regalo ninguno [...]. ${ }^{45}$

Além de negar a existência de remédios, uma vez que os expedientes utilizados não se enquadravam nos padrões europeus, o registro atesta a crença na intercessão divina e na eficácia das orações, coerente com a percepção de cura dos missionários e de eficácia da "magia eclesiástica”. Deve-se considerar também que não só eles consideravam natural invocar a ajuda de Deus, como também recebiam com naturalidade a misericórdia divina.

Em sua obra "Os Reis Taumaturgos", Marc Bloch (1924) lembrava que os ritos de cura não podem ser pensados e considerados fora das superstições que formam o "maravilhoso" de uma época e das "tendências gerais da consciência coletiva".

Entendemos que as curas realizadas pelos missionários jesuítas nas reduçōes da Província do Paraguai devem ser analisadas a partir desta perspectiva, podendo-se acrescentar algumas indagações - os missionários realmente curavam? Se não curavam, como mantiveram a crença em seus poderes? Há que considerar que os missionários referiram essencialmente os casos de doentes que se disseram (e se mostraram) curados após a intercessão dos santos, da água benta, do batismo ou das relíquias sagradas. Não há qualquer referência aos insucessos nas tentativas de curas, ou então, menção 
a recidivas de doenças, o que atestaria que a terapêutica empregada não havia sido eficaz, levando o indígena a repeti-la, ou então, a desacreditá-la. Quando as doenças cediam ou pareciam ceder, dando a 'ilusão da cura”, se estabelecia uma relação entre fé e milagre, entre pecado e perdão, entre conversão e cura.

Em relação a muitos desses registros - de cura de indígenas dados como mortos -, deve-se considerar a tendência natural do corpo humano de se livrar de algumas doenças sem auxílio externo. Muitos dos achaques curados milagrosamente pertenciam àquela espécie que só o tempo podia curar, tais como as febres e as feridas abertas. ${ }^{46}$ Deve-se, ainda, considerar que as potencialidades dos medicamentos disponíveis eram muito restritas e que muitas das doenças e das curas estavam associadas à fantasia e à imaginação. ${ }^{47}$

Em carta do Pe. Marcial de Lorenzana ao Provincial Pe. Diego de Torres, de 19 de julho de 1610, estes aspectos podem ser observados, permitindo, inclusive, uma aproximação com os reis taumaturgos de Marc Bloch:

Esta reducción, a 'toto genere' va cada dia mejor, y los indios y indias se pasan de muy buena gana al asiento nuebo. Despues de mi buelta se han animado mucho, y dicen q. han conocido ya el grande amor que les tengo, va acudiendo mas gente, muestran deseo de baptismo, no se nos muere nadie en las enfermedades, los que se han baptiçado in "articulo mortis' han sanado, tienen gran devoción con los evangelios y dicen que quando el Pe. les pone las manos en la cabeça les pone una cura con que ellos sienten q. los sanan; los q. tenian dos mugeres las van dejando y hacen otras cosas en que dan muestras de temer a Dios. ${ }^{48}$

Curiosa é também a crença numa "certa predestinação" dos jesuítas como médicos do corpo e da alma, e que os livraria do contágio em situações de epidemia. Isso fica evidenciado na ânua referente aos anos de 1653 a 1637 :

Mientras tanto se declaró una epidemia que hizo gran estrago. [...] El contágio se hizo tan general en la ciudad que postró también a todos los sacerdotes, menos a los de la Compañía, para que pudiesen asistir a los moribundos. No hicieron solamente esto, sino repartieron medicinas para los enfermos, y limosnas a los pobres. ${ }^{49}$ 
A documentação revela, ainda, a relação que se estabeleceria entre as curas realizadas, o prestígio que elas conferiam aos padres e as conversões delas resultantes. Este registro extraído da Ânua de 1632 - 34 refere-se à prática da sangria, sua assimilação pelos indígenas, bem como às formas encontradas por eles para manifestar sua gratidão. A associação da prática da sangria à oferta de alimentos, admitida pelo próprio missionário, é mais uma vez apresentada como determinante para a permanência nas reduçóes e para o abandono de suas antigas práticas.

Valió mucho para que no pereciesen todos la industria del Padre Pedro de Mola, provo a sangrarles y sanaron algunos y así se llenava todos los días nuestra casa de apestados que acudían ansiosos y deshados para que el Padre les diese de comer y les sangrase por sus manos pidiendo todo el pueblo a vozes a Nuestro Señor misericordia y muchos por aquel medio la alcançaron y derramandose por la tierra adentro la fama acudían los jentiles a tropas para que el Padre exercitase con ellos la misma piedad [...] los quales no sabiendo como agradecerlos todo el dia se andavam tras de el Padre haziendole mil carícias y allagos y la puerta de casa muchos regozijos y fiestas las noches a su usanza para tenerle contento y los ya cristianos dexandose formar de su doctrina en toda piedad cristiana y cortar lo vicioso y uvo muy señaladas conversiones y los jentiles disponiendose con gran fervor para el baptismo. ${ }^{50}$

As descrições do cotidiano das reduções nos períodos de fome e de epidemias referentes às primeiras três décadas do século XVII apontam para a estreita relação que se estabeleceu entre elas.

Los alegres principios no pudieron desarrollarse bastantemente a consecuencia de las calamidades públicas, tales como la pérdida de la cosecha y las epidemias. Por casi un año entero no había sino escenas tristes, caminando la gente flacos como esqueletos, o más bien a semejanza de cadáveres vivos. Había tres mil cristianos, de los cuales muchos se murieron, para irse al cielo. ${ }^{51}$

Interessante observar que tais momentos são igualmente propícios às experimentações e improvisações nas condutas terapêuticas. Ao lograrem êxito, como evidenciado no registro feito por Montoya de "uma medicina especial para a peste e fome", "um verdadeiro remédio para a disenteria", serão percebidas como socorro divino. A despeito de a ocasião favorecer a 
reavaliação e a reorganização do saber em relação à profilaxia e à terapêutica, isto é, em relação à saúde e à cura ("é salobre por sua natureza, muito gostosa, e favorece a origem de bom sangue"), a "medicina especial para a peste e fome" foi absorvida pelo discurso providencialista. ${ }^{52}$

Os missionários se dedicam, principalmente, a enfatizar os prejuízos que a fome e as epidemias causavam ao projeto reducional, como fica expresso nesta passagem:

Perecia de ambre el pueblo [...] Los mas dellos com esta ocasion desampararon el pueblo, i recurieron por comida a los sembrados de sus tierras antiguas, donde no avia llegado esta plaga, i se vieron los padres en mucho trabajo para hacerlos volver a la redución porque alegaban se cansaban en sembrar pues los ratones lo destruian todo. ${ }^{53}$

O comprometimento da conversão dos indígenas fica igualmente visível na interpretação supersticiosa dada à praga de ratos, pois, na perspectiva dos missionários, "al tiempo de sembrar, aparecieron enjambres de ratones, nacidos por la sequía, y comenzaron a devastar los campos, por lo cual que algunos víctimas de su superstición lo atribuyeron a brujería" ${ }^{4}$.

Se, por um lado, o retorno aos "sembrados de sus tierras antiguas" prejudicava o trabalho dos missionários, de outro, favorecia os magos que atribuíam aos missionários a responsabilidade pela fome e pelas epidemias, e prometiam restaurar a felicidade perdida. ${ }^{55}$

Mucho trabajo les causó cierto célebre hechicero llamado Yaguacaporo, el cual propaló que era una divinidad, y que se le debia venerar como a dios, asseverando que él había hecho el cielo y la tierra, y que el podía producir buon tiempo y mal tiempo, y que era dueño de vida y muerte. ${ }^{56}$

Em relação a esta disputa pelo controle da saúde e da doença, é preciso, ainda, reconhecer que "un solo médico no podía dar atención eficiente a cien mil indios, ni siquiera a la mitad" e isso pode significar "que las recetas y soluciones indígenas debían ser de uso general" 57 , o que permitia a sobrevivência das práticas curativas xamanísticas, bem como a receptividade às prédicas dos magos. ${ }^{58}$ Como estratégia empregada para contornar os problemas decorrentes da impossibilidade de o médico atender a todos em uma situação de epidemia, os missionários: 
Formaron con esta ocasión [...] entre los indios, cuadrillas de dos enfermeros, gente ya de madura edad, sanos, robustos y piadosos, para el servicio de los enfermos, y para investigar si los había en las casas, campos y selvas. Al mismo tiempo estos enfermeros eran los mejores propagadores de las prácticas religiosas. Llevaron a los enfermos a los Padres, para que rezaran el Evangelio sobre ellos, y procuraron que nadie muriese sin sacramentos. ${ }^{59}$

A contestação (e perseguição) aos magos guaranis ("hombres-dioses") que "profieren amenazas apocalípticas" ${ }^{60}$ se deveu, não tanto às ervas, poções e bálsamos por eles empregados nas curas (terapêutica curativa), mas à atribuição da realização de milagres aos magos/messias, à "tradicional veneración de los restos óseos de los grandes chamanes" ${ }^{61}$, associada e agravada ainda pela pretensão de conduzir os índios ao Paraíso, salvando-os das enfermidades. Foram, sem dúvida, a mística envolvida nas curas e os rituais mágicos que garantiam sua eficácia que causaram a oposição dos missionários. Daí ser possível perceber o confronto entre xamãs e missionários, como uma disputa de saberes e poderes, pelo controle das doenças e pela manipulação das curas e não-curas. ${ }^{62}$

Esta passagem da Carta Ânua, relativa à Redução de Nra. Sra. de la Natividad del Acarayg refere-se à prática do ritual xamanístico de cura, bem como ao reconhecimento da eficácia de aplicação ${ }^{63}$ :

Quando yo pase por esta reducion [para el Guayrá] me informaron los Pes. que eran muchos los hechiceros della en particular de una canalha que entre ellos llaman chupadores, porque com embustes i engaños que usan hacer creer a los ignorantes, que chupando a los enfermos la parte doliente, sale a fuera el humor maligno, llevando ellos para esto prevenido en la boca alguna cosa que lo parezca. ${ }^{64}$

Interessante observar que decorridos já dez anos desta referência feita aos chupadores, o redator da Ânua de 1637 - 39, o Pe. Francisco Lupercio de Zurbano, destacou a continuidade da prática ${ }^{65}$ :

Su inclinación a la superstición, a la flojera, y a sus costumbres antiguas, les hacía casi ineptos para la religión. [...] había una especie de superstición muy arraigada entre ellos, que consistía en llamar, en caso de enfermedad, a los hechiceros para que los sanaran. Estos médicos 
diabólicos no saben nada de medicina, sino que simulan inícuamente que chupan algo del cuerpo del enfermo, para que sane. ${ }^{66}$

$\mathrm{Na}$ medida em que, não propriamente os recursos medicinais sofreram contestação, mas sim sua eficácia ritual, os registros feitos pelos padres jesuítas, ao longo do século XVII, revelam uma absorção cada vez maior da farmacopéia (ervas, resinas e folhas), bem como da terapêutica empregada pelos indígenas, com algumas adaptações, como nos casos dos ferimentos expostos e das otites e conjuntivites decorrentes da varíola. ${ }^{67}$

Considerando que as práticas terapêuticas adotadas pelos indígenas americanos "estaban de acuerdo con el concepto de enfermedad que, entre otras, incluía el ayuno, la dieta, los baños, y sobre todos las drogas de origen vegetal [...]; y como ya se ha dicho no por su efectividad famacológica, sino por el atributo mágico" percebe-se por que "la medicina que llevaron los conquistadores, especialmente los misioneros, debido a su mística religiosa, fue la que mejor se adaptó al concepto indígena de la enfermedad"68. Em decorrência desses aspectos propiciadores da adaptação que a medicina e a farmacopéia das reduções jesuíticas foram consideradas das mais notáveis em seu tempo. ${ }^{69}$

Há que se considerar que a medicina presente nas reduções jesuíticas "unió al ingrediente mágico el recurso a los remedios vegetales que eran similares a los utilizados por la tradición medieval de los herbanarios monásticos, cuyo estudio había resurgido con gran vigor al comenzar el Renacimiento" 70 , mas, sobretudo, deve-se ressaltar que por iniciativa dos missionários e boticários foram identificadas as plantas medicinais e seus usos para incorporação no sistema médico tradicional, baseado na medicina humoral "por la cual cada medicamento tenía una cualidad, fria, cálida, seca o húmeda y un grado de exponente del uno al cuatro" ${ }^{71}$. Este registro que consta da Ânua referente aos anos 1635 - 1637 destaca as experiências com medicamentos feitas por um jesuíta enfermeiro.

[...] porque como el havia sido enfermero tantos años y tenia tanta experiencia y notable aplicacion a su offo y com su mucha claridad avia aprendido leido y experimentado medicamentos para acudir a los enfermos y nesecitados y nro. Sr. se avia comunicado acerto en el curar, los seglares teniam extraordinaria fee com sus curas esperando buen suceso 
en todo lo que el $\mathrm{H}$. Blas ponia su mano, atribuindolo a su virtud y religion $[\ldots] .72$

As Ânuas referentes às primeiras duas décadas do século XVII informam também sobre o uso de dois medicamentos, identificados como a "tierra de San Pablo" e o "licor de S. Nicolas", empregados pelos missionários para curar "algunas mordeduras de víboras", com o que deixavam os indígenas "ganados i acreditado el Sto. Evangelio" 73.

Diante destas observações, compreende-se a importância das curas "milagrosas", sobretudo dos indígenas que haviam sido atacados por cobras, bem como os desdobramentos das mesmas, evidenciados na disposição à conversão, como registrado na Conquista Espiritual do Pe. Montoya.

Una cobra venenosa tinha picado 'de morte' um índio no pé. Caiu este como morto, destilando de ambos os pés e dos olhos, ouvidos, narizes (narinas), boca e demais partes do corpo muito sangue. [...] Nestas condiçôes confessou-se e, como em último transe, recebeu com extrema devoção os óleos dos enfermos. Com a mesma piedade e não pequena instância pediu, em seguida, que o levassem à igreja, visto que queria despedir-se desta vida assistindo ao santo sacrifício da missa. Vendo ser tanta a sua devoção, o padre acabou cedendo, e num lugar próximo e decente celebrou a missa, que o doente ouviu, ficando são na hora. ${ }^{74}$

Apesar dos sucessos obtidos através da "magia eclesiástica” e das "experiências medicinais", os missionários tinham consciência de "sus limitaciones y por eso se preocuparon cuanto antes, traer de Europa hombres especializados en la ciencia médica" ${ }^{75}$. Esta preocupação teria se materializado na solicitação de envio de médicos, enfermeiros e boticários às missões, encaminhada ao Padre Geral da Companhia de Jesus, em 1632. Referindo-se, em especial, à atuação da Companhia de Jesus no Brasil, Serafim Leite informa sobre enfermeiros e boticários nas aldeias e colégios jesuítas:

[...] havia lei da Companhia que todas as aldeias de índios dispusessem de enfermaria. Quando não era casa à parte, junto da residência havia algum Padre ou Irmãos com medicamentos para os índios enfermos. E tanto nos Colégios como nas Aldeias, os Irmãos enfermeiros deviam prestar os primeiros curativos de urgência em caso de ferimentos, e o faziam segundo a sua aptidão pessoal, enquanto não se recorria ao médico ou 
cirurgião nas terras em que os havia. [...] No Brasil, além das duas modalidades de enfermeiros e cirurgiōes da Companhia, havia as Boticas. [...] no Brasil elas nasceram sobretudo duma necessidade local. A princípio os medicamentos vinham do Reino já preparados. Mas as piratarias do séc. XVI e as dificuldades da navegação impediam com freqüência a vinda dos navios de Portugal, e era preciso reservar grandes provisões $[\ldots] \cdot{ }^{76}$

Isto explica por que, apesar das dificuldades em compreender as práticas da terapêutica indígena e das restrições na aplicação de sua farmacopéia (definidas por princípios religiosos), os herbários e boticários das Missões Jesuíticas são admirados por cronistas e historiadores como Azara, Lozano e Guevara.

Ainda segundo Serafim Leite, isto se deveu à imperiosa necessidade de contornar a inconstância das remessas de medicamentos da Europa, o que por um lado "obrigou [...] os Jesuítas a terem abundante provisão de medicamentos; e também logo a procurarem os que a terra podia dar, como as suas plantas medicinais, que começaram a estudar e a utilizar em receitas próprias [...] Destes remédios e tisanas, iniciadas no século XVI, se foi pouco e pouco ampliando a preparação de outros, com ingredientes europeus e da terra, até se estabelecer a farmacopéia brasileira [...]"77. Em relação aos boticários existentes nos Colégios e nas Reduções é ilustrativo o registro feito na Ânua de 1637 - 39:

Así trabajan los mestros incansablemente en provecho de las almas, siendo al mismo tiempo muy frecuentada la portería por los pobres y hambrientos que hallan allí alivio en sus sufrimientos materiales. Se les reparte, sean pocos o sean muchos, alimentos en abundancia; no pocas veces también abrigos para cubrirse. Esto para los sanos. Para los enfermos empero, hay una botica especial en casa, de donde se reparte gratis toda clase de medicinas. Asó logra la Compañía aucir a todas las necesidades humanas, las del alma y las del cuerpo, todo por amor a Dios y por caridad para con el prójimo. [...] Estas cosas suceden en casa. Fuera de ella no se hace menos. Continuamente son llamados los nuestros al campo y a las estancias [...] para sistir a los enfermos, tanto espiritual como corporalmente. Pues, fuera del alimento de las almas les suministran medicinas y alimentos convenientes. ${ }^{78}$ 
Esse registro, que alude a uma medicina desprovida de atribuições mágicas, merece ser cotejado com o do Pe. Provincial Andres de Rada, que refere a cura de índios atingidos por uma epidemia pela ingestão de água "tocada con cierta esquela", no ano de 1663:

El pueblo de Santa María sufría mucho por cruel peste [...] Y todavía no se veía mengua del contagio, cuando se les ocurrió a los Padres, combatirlo de un modo. Estaba a la mano un libro, recién publicado, del Padre Juan Eusébio (intitulado Opera Parthenical). Leíalo uno de los Padres y en el septimo opúsculo, epist 10, pág 409, encontró que a muchos era saludable remédio água tocada con cierta esquela con la inscripción: In conceptione tua, Virgo immaculata fueste. Ora pro nobis Deum, cujus filium pereriste. ¡Cosa maravillosa! Se tomaba el água con aquella esquela, y al instante amaenó aquella calamidad, tanto que nadie fue atacado por la epidemia, y los postrados en cama para esperar su último instante, recobraron sus fuerzas y sanaron. ${ }^{79}$

Dentre as possíveis razões para a manutenção e divulgação entre os "iniciados" de práticas curativas de caráter mágico, conforme fica atestado na obra "Opera Parthenical”, atribuída ao Pe. Juan Eusebio, deve-se privilegiar a que está associada à mudança de condutas dos indígenas e ao "cambio de sus sentimientos" decorrentes das curas milagrosas, através das quais "tan supersticiosa gente, se trocó en cristiana y de una fe tenacisima” ${ }^{80}$. Buscando exatamente esse efeito - o crescente "aprovechamiento en la fe y costumbres cristianas" ${ }^{81}$ — os missionários mantiveram nas reduções o uso de relíquias, da água benta e do sinal da cruz, por impressionarem, por sua eficácia, os indígenas.

Coube aos Padres Pedro de Montenegro e Segismundo Asperger (séc. XVIII) a organização de importantes catálogos das ervas medicinais e suas aplicações, sendo esses jesuítas os pioneiros na utilização da farmacopéia indígena e nas adaptações aos remédios europeus. ${ }^{82}$

Segundo o registro do ano de 1719, uma epidemia de varíola dizimou 17 mil índios, sendo que "[...] el padre Segismundo Asperger parte com los remedios traidos de Europa y parte com las yerbas medicinales del país, cuyas virtudes y propiedades conocía muy bien [...] había libertado de la muerte un gran número de personas [...]"83. Azara, referindo-se ao Padre Asperger, registra que "el hizo mil ensayos com todas las plantas, que es el 
medio de hallar específicos, y no el que usan en Europa valiéndose siempre de lo que hay en la botica [...]" ${ }^{84}$.

Pelo exposto, conclui-se que, não somente os Guarani reformularam suas atitudes diante da doença e da morte, mas também os missionários jesuítas vivenciaram, em especial em relação às práticas terapêuticas, uma oportuna e conveniente flexibilização que lhes permitiu controlar as doenças, manipular as curas e as não-curas e promover manifestações de piedade e de devoção coerentes com o projeto de civilização-conversão da Companhia de Jesus.

\section{Referências Bibliográficas}

ARATA, Pedro N. "Botánica Medica Americana. Los Herbarios de las Misiones del Paraguay." In: La Biblioteca, ano II, t. VII, Buenos Aires, 1898.

BERTONI, Moisés Santiago. "La Civilización Guarani. Parte II. Etnografia: Conocimientos." Puerto Bertoni/Alto Paraná, Paraguay: Imprenta y Edición "Ex Sylvis", 1927.

BIRABEN, Jean-Nöel. "Epidemias na História da População." In: MARCÍLIO, Maria L. (org.) População e Sociedade. Petrópolis: Vozes, 1984. p. 111-131. BLOCH, Marc. Os Reis Taumaturgos. São Paulo: Cia. das Letras, 1993. p. 27. BURKE, Peter. A Escola dos Annales (1929 - 89): A Revolução Francesa da Historiografia. 2a ed. São Paulo: UNESP, 1992.

CADOGAN, León. Ayvu Rapyta - Textos místicos de los Mbyá-Grani del Guairá. Biblioteca Paraguaya de Antropologia, Asunción, V, XVI, 1992.

CARTAS ÂNUAS DE LA PROVINCIA DEL PARAGUAY (1637 - 1639). Introducción del Dr. Ernesto J. A. Maeder. Buenos Aires: FECIC, 1984. CARTAS ÂNUAS DE LA PROVINCIA DEL PARAGUAY. Traducción de Carlos Leonhardt, 1927. (Mimeo).

CARTAS ÂNUAS DE LA PROVINCIA JESUÍTICA DEL PARAGUAY (1632 - 1634). Introducción del Dr. Ernesto J. A. Maeder. Buenos Aires: Academia Nacional de Historia, 1990.

CLASTRES, Pierre. "Mitos y Ritos de los Indios de America de Sur." In: Investigación en Antropologia politica. Barcelona: Gedisa, 1987. pp. 71-86.

COIMBRA Jr., Carlos E. A. "Ecologia humana e epidemiologia na Amazônia: uma abordagem bioantropológica." In: NEVES, Walter A. (org.). Origens, Adaptação e Diversidade Biológica do homem nativo da Amazônia. Belém: Museu Paraense Emílio Goeldi - Coleção Emilie Snethlage, 1991. pp. 179-192. CUNHA, Manuela C. da. Os mortos e os Outros. São Paulo: HUCITEC, 1978. 
DOCUMENTOS PARA LA HISTORIA ARGENTINA. Tomo XX (Iglesia). Buenos Aires: Talleres Casa Jacobo Preuser, 1924.

ECHENIQUE, Nora e FERREIRA, Miriam. "La medicina en las reducciones jesuíticas." V Simpósio Nacional de Estudos Missioneiros (1983). Anais. Faculdade de Filosofia, Ciências e Letras Dom Bosco, Santa Rosa, 1985, pp. 251-262.

FURLONG, Guillermo. Misiones y sus Pueblos de Guaranies. Buenos Aires: Teorema, 1962.

GARLET, Ivori José. "Mobilidade Mbyá: História e Significação." Dissertação de Mestrado apresentada ao Programa de Pós-Graduação em História Ibero-Americana da PUC, Porto Alegre, 1997.

HAUBERT, Maxime. "Indios y Jesuítas en el Paraguay." In: Suplemento Antropológico, v. XXII, n. 1, Asunción, Universidad Católica, Asunción, 1987, p. 241-264.

HOLLAND, William R. Medicina Maya en los Altos de Chiapas. Quito: Esteves Manuel Gutiérrez, 1989.

LE GOFF, Jacques. As doenças têm história. Lisboa: Terramar, 1990.

LEITE, Serafim. Artes e Ofícios dos Jesuitas no Brasil (1549 - 1760). Lisboa: Ediçôes Brotéria, 1953.

LEONHARDT S. J., Carlos. Los Jesuitas y la medicina en el Rio de la Plata. Estudios 57, Buenos Aires, 1937.

LÉVI-STRAUSS, Claude. Antropologia Estructural. Buenos Aires: EUDEBA, 1968. LÉVI-STRAUSS, Claude. Antropologia Estrutural II. Rio de Janeiro: Tempo Brasileiro, 1975.

MAEDER, Ernesto J. A. (org.) Cartas Anuas de la Provincia del Paraguay, 1632-1634. Buenos Aires: FECIC, 1990.

MELIÀ, Bartomeu. El Guarani Conquistado y Reducido. Ensaios de Etnohistória. Asunción: Biblioteca de Estudios Antropológicos de la Universidad Católica, v. 5, 1986.

MÉTRAUX, A. "La Causa y el Tratamiento Mágico de las enfermedades entre los índios de la Región Tropical Sud-americana." In: América Indígena, v. $I V$, n. 2 abril, 1944, pp. 157-164.

MONTOYA, Antonio Ruiz de. Conquista Espiritual. Porto Alegre: Martins Livreiro, 1985.

MONTOYA, Antonio Ruiz de. Vocabulário y Tesoro de la Lengua Guarani. I Arte y Bocabulário de la Lengua Guarani. Viena: Faesy y Frick; Paris: Maisonneuve, 1876. 
NOELLI, Francisco Silva. Para uma etno-história das epidemias entre os Guarani causadas pela presença européia. Mimeo, 1999.

PALACIOS, Sílvio. "Contribución de la Arqueologia medica al estudio de las ruinas de las misiones jesuítico-guaraníes de Argentina, Brasil y Paraguay." In: Estudos Ibero-Americanos, PUCRS, v. XX, n. 2, dez./1994, pp. 45-64. PASTELLS, R. Pablo S. J. Historia de la Compañia de Jesús en la Provincia del Paraguay. Madrid: Librería General de Victoriano Suárez, 1912, tomo I. RABUSKE, Arthur S. J. "A Carta Magna das Reduções Jesuíticas Guaranis." In: Estudos Leopoldenses, São Leopoldo, v. 14. n. 47, 1978, pp. 21-39. SCHÄRER, Lídia C. "San Ignacio y los milagros en la salud a traves de las Cartas Anuas (1626 - 1639).” VIII Simpósio Nacional de Estudos Missioneiros. Anais. Santo Ângelo: 1989. pp. 257-261.

SUSNIK, B. "Cultura religiosa" (ambito americano). Asunción: Manuales del Museo Etnográfico Andres Barbero, 1989.

TÉLLEZ, Carmen Sánchez. La Medicina en las Lenguas Americanas y Filipinas Prehispanicas. Madrid: Publicaciones de la Universidad de Alcalá de Henares, 1994.

THOMAS, Keith. Religiāo e o declínio da magia. Crenças populares na Inglaterra - séculos XVI e XVII. São Paulo: Cia. das Letras, 1991.

VARA(h), Alfredo. La construcción guarani de la realidad - una interpretación psicoanalítica. Asunción: Centro de Estudios Antropológicos, v. 3, 1984.

VIANNA, Hélio. Jesuitas e Bandeirantes no Uruguay (1611 - 1758). MCA IV, 1970.

\section{Notas}

${ }^{1}$ Furlong, 1962, p. 604.

${ }^{2}$ De acordo com Furlong, os Guarani tinham seus médicos e "medicinas, estribando casi todas estas en el uso de cortezas, semillas, jugos de plantas y árboles de la región" (Furlong. Apud Echenique e Ferreira 1985, p. 252). Nora Echenique e Miriam Ferreira referem a utilização de ungüentos contra mosquitos e como protetor solar, além das escarificações feitas com "espinhas de pescados, aguijones de palmera o dientes de acutí, combatendo así la pesadez del cuerpo y el cansancio mismo", da "curación ignea" na cauterização de feridas; das ventosas e dos anti-helmínticos que viriam a ser empregados por toda a população colonial americana. (Idem, p. 252).

${ }^{3}$ Cadogan, 1992, p. 182-185. Ver Echenique e Ferreira, 1985, p. 251 a 262: Este estudo refere-se a terapêutica empregada pelos guaranis e pelos missionários jesuítas em relação à disenteria, picadas de cobras, tratamentos oculares e para dores de ouvido, bem como para a cicatrização de feridas. 
${ }^{4}$ Cadogan, 1992, p. 112. Roque Laraia registra o costume: "a chegada de um estranho em determinadas comunidades pode ser considerada como a quebra da ordem social ou sobrenatural. Os xamã Suruí (índios Tupi do Pará) defumam com seus grandes charutos rituais os primeiros visitantes da aldeia, a fim de purificá-los e torná-los inofensivos". (Laraia, 1986, p. 76). ${ }^{5}$ Cadogan, 1992, p. 230.

${ }^{6} \mathrm{O} \mathrm{P}^{\mathrm{e}}$. Sepp acreditava que "la mayoría de los indígenas morían de parasitasis, debido a la voracidad con que consumían la carne semicruda, estas se pudren en el estómago y donde hay carne corrompida existen las lombrices y al aumentarse estas el estómago no retiene nada más lo que produce la desintería sangrienta (fluje de vientre com pujos y sangre mezclada)" (Echenique e Ferreira, 1985, p. 254). Segundo estas mesmas autoras, "la parasitosis reducía las expectativas de vida de los indígenas, a no más de cincuenta años”. (Idem, p. 255)

${ }^{7}$ Furlong, 1962, p. 604. De acordo com Echenique e Ferreira: "La viruela hemorrágica y negra es una enfermedad que se caracteriza por una erupción de pústulas com costras que al caer, acostumbran a dejar un hoyo en la piel." (Echenique e Ferreira, 1985, p. 253).

${ }^{8}$ Conforme Biraben: "Algumas das maiores doenças epidêmicas que pontilhavam tragicamente a humanidade foram, sem dúvida, a peste bubônica, a varíola, a gripe, a disenteria, o tifo e a sífilis. [...] A varíola caracteriza-se, entre as epidemias infecciosas, pela erupção de pústulas em todo o corpo, pela alta letalidade e grande contagiosidade. [...] No século XVII, Thomas Sydenham [...] inova na terapêutica, pois constata que grande número de pústulas, consideradas até então como uma força favorável da natureza para expulsar o veneno, era, ao contrário, um sinal desfavorável. Então ele suprime as sangrias e purgativos, até então usuais no tratamento inicial da moléstia [...]”. (Biraben, 1984, p. $111-131$ ).

${ }^{9}$ Haubert, 1987, p. 254.

${ }^{10}$ Leonhardt, 1937, p. 101. De acordo com Leonhardt: “[...]el Derecho Canónico [...] refleja la legislación de siglos al ordenar que 'los clérigos han de evitar, no sólo lo que es indecoroso, sino también lo que es ajeno a su estado. Sin indulto apostólico no deben ejercer la medicina ni la cirurgía. [...] Dice el canon 985: 'Son irregulares por delito los clérigos que ejercen la medicina o la cirurgía a ellos prohibida, si ejerciéndola causan la muerte.” (Leonhardt, 1937, p. 102).

${ }^{11}$ Leonhardt, 1937, p. 103.

${ }^{12}$ Apud Leonhardt, 1937, p. 104.

${ }^{13}$ Leonhardt, 1937, p. 110.

${ }^{14}$ Apud Rabuske, 1978, p. 24.

${ }^{15}$ Em razão disso, encontraremos os missionários que, "con más buena voluntad que ciencia adecuada, acudían al alivio de los enfermos” (Furlong, 1962, p. 604), aplicando sangrias, tão logo fosse constatada a epidemia. Considerada como cura profilática, exigiu a confecção de sangradores e o recrutamento de enfermeiros nas reduçóes, mas o próprio Padre Sepp, que enfrentou a peste de varíola em 1695, constatou que elas não se constituíam em remédios eficazes contra este mal.

${ }^{16}$ Segundo Echenique e Ferreira, "en materia médica los europeos no estaban más adelantados que los guaraníes” (Echenique e Ferreira, 1985, p. 251), o mesmo valendo particularmente para a medicina espanhola que "no estaba muy avanzada", sendo bastante comuns os curandeiros que, valendo-se de amuletos e talismãs, "asombraban a los galenos". (Idem, p. 252). 
${ }^{17}$ D. H. A., Tomo XX, 1924, p. 681.

${ }^{18}$ Haubert, 1987, p. 254.

${ }^{19}$ As doenças afetaram intensamente a dinâmica populacional dos Guarani que, conforme as fontes coloniais, estavam em crescimento nos séculos 16 e 17. Cabe aqui fazer referência ao estudo de arqueologia médica realizado por Silvio Palacios que contribui para o conhecimento sobre a saúde e a enfermidade dos guaranis nas reduçôes jesuíticas e que leva em conta que: "La característica de urbanización de los pueblos misioneros jesuítico-guaraníes, con la localización, generalmente uniforme, de la casa de los Padres, el Templo y el Cementerio, el número de habitantes, los años de existencia, la mortalidad comprobada y la seguridad que la gran mayoría eran enterrados en el cementerio de esqueletos de muestras óseas y otros vestigios podría estar asegurada" (Palacios, 1994, p. 54). "La mortalidad en las poblaciones antiguas, incluyendo la de las misiones jesuítico-guaraníes, era alta y los índices por grupos de edad atarían elevados con predominio de niños, jóvenes y adultos no muy mayores” (Idem, p. 46). ${ }^{20}$ Melià, 1986, p. 57.

${ }^{21}$ Melià, 1986, p. 87. Garlet observa que “os próprios missionários eram, em muitos casos, os agentes transmissores de doenças. Em algumas circunstâncias o efeito das epidemias frustrava as suas expectativas, enquanto que em outras assinava o aval de seu ingresso nas aldeias, sendo tomados por grandes pajés que sabiam como tratar estas novas e estranhas doenças. [...]”. Por outro lado, "as epidemias, em muitos casos evacuavam as populações nativas de extensas áreas, liberando-as aos colonizadores. Acompanhando o histórico dos contatos entre os antigos Mbyá com a sociedade colonial, fica evidente que os colonos foram se estabelecendo sobre seu território à medida que as doenças produziam verdadeiras clareiras demográficas." (Garlet, 1997, p. 40-41).

${ }^{22}$ Coimbra, 1991, p. 182.

${ }^{23}$ Coimbra, 1991, p 179.

${ }^{24}$ A delimitação espacial observada neste estudo abarca a Antiga Província Jesuítica do Paraguay, inicialmente chamada de Província do Paraguay, Chile y Tucumán, correspondendo aos territórios hoje ocupados pela Argentina, Uruguai, Paraguai, Chile, a parte meridional da Bolívia e os estados brasileiros do Rio Grande do Sul, Santa Catarina, Paraná e Mato Grosso do Sul.

${ }^{25}$ Apud Vianna, 1970, p. 129.

${ }^{26}$ Apud Vianna, 1970, p. 123.

${ }^{27}$ Apud Vianna, 1970, p. 128-129.

${ }^{28}$ Apud Vianna, 1970, p. 112. F. Noelli, em estudo sobre o impacto das epidemias entre os Guarani, afirma que "em vez de evitar os contatos, impedindo a contaminação, fruto da ignorância científica da época, não só os padres como os índios contaminados iam continuamente às aldeias, que muitas vezes ainda poderiam estar livres das doenças" (Noelli, 1999, p. 5).

${ }^{29}$ Montoya, 1876.

${ }^{30}$ Também Carlos Gatti, médico e etnógrafo dos Guarani do Paraguai, atribui o sentido dado por Montoya, $\underline{\text { mbava }}=$ "mortandad, peste, epidemia" (Gatti, 1985).

${ }^{31}$ Coimbra, 1991, p. 184.

32 Téllez, 1993, p. 19. 
${ }^{33} \operatorname{Vara}(\mathrm{h}), 1984$, p. 97.

${ }^{34}$ Conforme Clastres, "el pensamiento indígena determina [...] la enfermedad como ruptura de la unidad personal alma-cuerpo, y la curación como restauración de esa unidad. [...] Para ciertos pueblos, los Guaraníes por ejemplo, el alma [...] se confunde con el nombre própio: el alma es el nombre. Así, una enfermedad particularmente grave puede ser diagnosticada como inadecuación del nombre a la persona enferma. La causa de la enfermedad es el error de denominación, el enfermo no posee el nombre-alma que le conviene. [...] La cura prueba que efectivamente ha encontrado el verdadero nombre [...]" (Clastres, 1987, p. 81).

${ }^{35}$ Cadogan, 1950, p. 235.

${ }^{36}$ Cadogan, 1992, p. 137.

${ }^{37}$ Montoya, 1985 , p. 25.

${ }^{38}$ Montoya, 1985, p. 54.

${ }^{39} \mathrm{O}$ xamã é também percebido pelos Guarani como "un ser temible, capaz de destruir a sus enemigos a leguas de distancia, su capacidad para realizar hechizos y destruir es ilimitada, y la amenaza de ser víctima de ellos está constantemente en la mente Guarani” (Vara(h), 1984, p. 98).

${ }^{40}$ Montoya, 1985 , p. $54-55$.

${ }^{41}$ Thomas, 1991, p. 527.

42 Thomas, 1991, p. 181.

${ }^{43}$ Thomas, 1991, p. 527.

${ }^{44}$ D. H. A., Tomo XX, 1924, p. 290. Lídia Schärer em seu artigo "San Ignácio y los milagros en la salud a traves de las Cartas Anuas (1626 - 1639)" afirma: "la imagen de San Ignacio, es imagen del acto evangelizador" (Schärer, 1989, p. 257) e refere que sua manifestação curativa se estendia a "fracturas, fiebre crónica, ceguera y otras dolencias de la vista, parálisis de ambos miembros inferiores, dolores crónicos de cabeza; así como también acudia con las enfermedades mentales y como patrono protector de las mujeres embarazadas". (Idem, p. 259).

${ }^{45}$ D. H. A., Tomo XX, 1924, p. 294.

${ }^{46}$ Vale aqui referir as observaçôes de Jacques Le Goff sobre as curas das escrófulas pelo toque régio tratadas por Marc Bloch em "Os Reis Taumaturgos”: "Às vezes, as doenças mais ou menos confundidas sob o nome de escrófulas ou alporcas curavam-se espontaneamente, se bem que amiúde de forma incompleta ou temporária. A natureza fazia o milagre. Como em geral a cura acontecia bastante tempo depois do cumprimento do rito de cura, as pessoas acreditavam facilmente na realidade de um milagre retardado". (Le Goff in Bloch, 1993, p. 27). Pode-se aqui estabelecer uma aproximação entre as curas milagrosas referidas por Bloch e as registradas pelos missionários nas Cartas Ânuas, na medida em que, em alguns casos, a "natureza" promovia a melhora do doente.

${ }^{47}$ Em relação a este ponto, é preciso ressaltar que a medicina de outrora era praticamente incapaz de descobrir e de avaliar as recidivas das doenças. Além disso, os médicos, à época (séc. XVII), não tinham a sua disposição nem uma terminologia muito rigorosa, nem métodos de diagnóstico muito seguros. Havia, segundo Marc Bloch, algumas doenças capazes de facilmente dar a ilusão de cura, "pois com bastante frequiência suas manifestaçôes [...] desaparecem de forma espontânea, ainda que para reaparecer mais tarde”. (Bloch, 1993, p. 277). Numa 
referência ao que denominou "explicação psicoterápica do milagre régio", Bloch nos lembra que: "No tempo em que os reis da Inglaterra benziam os cramp-rings, decerto se confundiam sob o nome de epilepsia [...] muitas outras desordens nervosas [...] que tinham origem puramente emocional ou que a neurologia moderna incluiria no grupo de fenômenos nascidos da sugestão ou da auto-sugestão [...] todos eles acidentes que um choque psíquico ou a influência sugestiva de um talismã são perfeitamente capazes de fazer desaparecer. [...] Segundo tudo indica, alguns dos usuários dos anéis deveram sua cura (ou talvez a atenuação de seus males) muito simplesmente à robusta fé que haviam devotado ao amuleto régio". (Idem, p. 272). ${ }^{48}$ Apud Pastells, 1912, p. 163.

${ }^{49}$ D. H. A., Tomo XX, 1924, p. 523.

${ }^{50}$ Maeder, 1990, p. 167.

${ }^{51}$ D. H. A., Tomo XX, 1924, p. 658.

${ }^{52}$ Montoya, 1985, p. 141-145. De acordo com Bertoni, "Conviene recordar aquí un hecho interesante, que dejaría evidenciado el buen efecto del Kaá-hái, o Agrial, planta que debe su agradable acidez al ácido oxalico principalmente. Cuando el célebre Padre Montoya llegó a orillas del Yabebi-ry (Misiones, Argentina), con unos 10.000 prófugos del Guaihrá, se declaró tan recia epidemia de disentería, que murieron más de 2.000 de aquellos neófitos. Como faltasen víveres, los Guaraníes dieron en comer aquella suculenta verdura [...] El caso es que pronto se notaron los buenos efectos sobre la epidemia [...]”. (Bertoni, 1927, p. 338).

${ }^{53}$ D. H. A., Tomo XX, 1924, p. 287.

${ }^{54}$ D. H. A., Tomo XX, 1924, p. 591.

55 Já se disse, muitas vezes, que os xamãs — viajantes no tempo e no espaço — são tradutores e profetas. Cabe-lhes, sem dúvida, interpretar o inusitado, conferir ao inédito um lugar inteligível, uma inserção na ordem das coisas. Essa ordenação não se faz, contudo, sem contestação e, freqüentemente, é objeto de ásperas disputas que se assentam tanto na política interna quanto nos sistemas de interpretação. Esta disputa será reatualizada com a chegada dos missionários. Por outro lado, de acordo com Manuela Carneiro da Cunha, observou-se, muitas vezes, o extraordinário florescimento do xamanismo em situações de dominação do tipo colonial, ou mais exatamente quando os povos indígenas foram capturados nas engrenagens do sistema colonial escravista.

${ }^{56}$ D. H. A., Tomo XX, 1924, p. 556.

${ }^{57}$ Echenique e Ferreira, 1985, p. 260.

${ }^{58}$ É oportuno lembrar que o medo e a desconfiança iniciais foram cedendo diante do "poder de cura” demonstrado pelos missionários frente às doenças desconhecidas e à ineficácia das práticas tradicionais de cura dos karaí nativos. Conforme Garlet, "não era a cura da alma ou do espírito que o demovia a aceitar o missionário, mas a cura dos males físicos”. (Garlet, 1997, p. 41).

${ }^{59}$ Maeder, 1984, p. 88.

${ }^{60}$ Haubert, 1987, p. 253-254.

${ }^{61}$ Haubert, 1987, p. 255.

${ }^{62}$ Deve-se ressaltar que a eficácia da cura xamânica depende do medicamento, mas que este não age autonomamente, senão como parte de todo o processo de cura xamânica. E é este 
processo que torna a cura socialmente aceitável, permitindo a atuação do xamã. Na verdade, qualquer fenômeno mágico é um fenômeno de crença e esta só pode nascer das necessidades coletivas do grupo. Marc Bloch, ao tratar dos rituais de cura em sua obra "Os Reis Taumaturgos", de 1923, nos alertava para a "a natureza profunda dos fenômenos sociais", reconhecendo que era mais revelador o fenômeno do milagre do que a cura em si. Ao analisar a questão da magia, Claude Lévi-Strauss (1968) ressalta que não se deve procurar a eficiência dos feiticeiros nos cânticos, poçōes ou misturas, pois a eficácia dos rituais reside no consenso que decorre do fato de o xamã curar por ser considerado por todos um grande xamã. O antropólogo refere ainda a importância do consenso social para o funcionamento do que denomina "complexo shamanístico" (Levi-Strauss, 1968, p. 162), isto porque o poder do xamã somente se mantém enquanto "cuenta con la fe y la participación de la comunidad" (Vara(h), 1984, p. 100). Para Lévi-Strauss, "la cura shamánica como una maniobra con un único protagonista", pois "el complejo shamánico se compone de tres protagonistas: enfermo, shamán y comunidad" (Lévi-Strauss, 1968, p. 162-163).

${ }^{63}$ É possível observar uma singular uniformidade no tratamento das enfermidades pelos xamãs desde as Antilhas à Terra do Fogo: "Culasquiera que sean las modalidades de las curaciones, terminan siempre con la extracción de un objeto patógeno mediante fumigaciones y succiones. Solamente cuando el alma ha sido robada, la técnica del shamán cambia; pero aún en tal caso no es raro que éste combine la busca del alma perdida con la extracción de la substancia mágica” (Métraux, 1944, p. 160). Cabia ao xamã a reversão desses feitiços e, caso se trate de feitiçaria, "los gusanos 'extraídos' se colocan en un tubo de 'takwara' entre viruta tapándolo, el shaman lo entierra cerca del fuego; el mismo calor del fuego mata a la 'enfermedad' y fulmina al respectivo hechicero, pero son Tupã y Jakairá quienes reprenden espíritus y almas arbóreas indóciles" (Susnik, 1989, p. 157).

${ }^{64}$ D. H. A., Tomo XX, 1924, p. 296.

${ }^{65}$ Em seu estudo sobre a medicina pré-hispânica, Carmen Tellez remete à uniformidade do tratamento das enfermidades, pelos xamãs sul-americanos, já apontada por Métraux: “Ante el enfermo procedía a hablar con él y con sus familiares para averiguar la causa del mal, después le palpaba todo el cuerpo y procedía a chupar la parte lesa para con este ritual extraer el daño. Mediante drogas alucinatorias, se ponía en contacto con los espíritus y prognosticaba el curso de la enfermidad" (Téllez, 1993, p. 110).

${ }^{66}$ Maeder, 1984, p. 87.

${ }^{67}$ Conforme Biraben: "Em 30\% dos casos, complicaçōes oculares podem provocar uma cegueira mais ou menos grave, quando houve ulceramento da córnea. Podem ocorrer ainda inflamações da retina, nevrites óticas, otites com surdez, orquites, hepatites, nefrites, problemas nervosos e mesmo paralisias e problemas nas articulaçôes." (Biraben in: Marcílio, 1984, p. 126). O mesmo autor refere que a partir do século 17, o médico Thomas Sydenham passa a administrar aos doentes um xarope à base de vitríolo e algumas gotas de láudano, que atenuavam a erupção. (Idem, p. 131). Ainda sobre a farmacopéia indígena destacamos sua "multivariedad asombrosa, y debemos citar además de la quina febrífuga, el yiquirití, las andirobas, el tabaco entre otros, la importancia que tuvo como agente terapeutico la yerba mate." (Echenique e Ferreira, 1983, p, 257.)

${ }^{68}$ Téllez, 1994, p. 20. 
${ }^{69}$ Sabe-se "que los indígenas utilizaban entre sus medicamientos la coca, el tabaco, y en especial la quina”, mas foram os missionários jesuítas "quien más hicieron por difundir sus beneficios; hasta el punto de que en la lengua inglesa la quina se conoce com el nombre de Jesuit's Bark, Jesuit's Tree, Jesuit's Powder." (Echenique e Ferreira, 1983, p. 251.)

${ }^{70}$ Téllez, 1993, p. 20.

${ }^{71}$ Téllez, 1993, p. 20. Conforme Téllez: "Esta patología humoral que pasó a las tierras conquistadas por España, fue curiosamente introducida, más que por médicos o boticarios, por los misioneros y el clero en general, que eran quienes en realidad asistían a los enfermos tanto en los hospitales como en los lugares más remotos, llevando a los indios además de su fe, un nuevo concepto de medicina. Los misioneros, hombres educados en las doctrinas de su tiempo, conocedores de las lenguas y la literatura clásicas y en contacto directo con el pueblo, fueron, pues, el vehículo adecuado para la difusión de la medicina homural”. (Téllez, 1993, p. 22). ${ }^{72}$ D. H. A., Tomo XX, p. 472.

${ }^{73}$ D. H. A., Tomo XX, 1924, p. 283-284. Conforme Bertoni: "Naturalmente las mordeduras de víboras constituian la mayor preocupación. Pero el número elevadisimo de plantas empleadas atestigua lo escaso y dudoso de los efectos. Lo cual era natural. Contrariamente a la opinión todavía muy arraigada (...) no existe ningún remedio seguro, ni vegetal ni outro, sobre el que se pueda contar para salvar la vida cualquier caso de mordedura de víboras. (...) Los remedios usados por los Guaraníes, contra el veneno ofídico, en cuanto a su acción efectiva, pertenecian a cuatro categorias diferentes, aunque alguno de ellos pudiese pertenecer a dos o tres categorias a la vez - la primera propendia a la eliminación del veneno; la segunda a su neutralización; la tercera a sostener la vitalidad, y la cuarta a prevenir los accidentes secundários y la infección general." (Bertoni, 1927, p. 357-358).

${ }^{74}$ Montoya, 1985, p. 224-225.

${ }^{75}$ Echenique e Ferreira, 1985, p. 258.

${ }^{76}$ Leite, 1953 , p. 84-85.

${ }^{77}$ Leite, 1953 , p. 86.

${ }^{78}$ Maeder, 1984, p. 33.

${ }^{79}$ Leonhradt, 1927, p. 102.

${ }^{80}$ Maeder, 1984 , p. 89.

${ }^{81}$ Maeder, 1990, p. 147.

${ }^{82}$ De acordo com Arata: "Los historiadores del Rio de la Plata (Lozano, Guevara, etc.), los viajeros (Azara, Demersay, Martin de Moussy, etc.) hablan todos com admiración unas veces, y con curiosidad e interes siempre de los Herbarios de las Plantas Medicinales de Misiones hechos por los padres jesuítas y transmitidos manuscritos de reducción en reducción, de convento en convento. (...) Los curanderos de la época colonial y aun nuestros médicos viejos, les atribuian grande importancia, a tal punto que se copiaban y volvían a copiar sigilosamente." (Arata, 1898, p. 430-431).

${ }^{83}$ Arata, 1898, p. 443.

${ }^{84}$ Apud Arata, 1898, p. 443. Bertoni chama a atenção, no entanto, para a importância da farmacopéia indígena para as inovaçōes da medicina moderna. "La creencia de que el conocimiento de las plantas medicinales de estos países se deba principalmente a los Padres Jesuítas, 
es bastante generalizada en el público de estos países. Sin embargo, es inexacta. Es indudable que los Jesuítas hicieron mucho; pero fue en el sentido de recoger las informaciones de los Indios, someterlos al crisol de la experiencia, y transmitirlas." (Bertoni, 1927, p. 382).

\section{Resumo}

Este artigo tem como objetivo principal apresentar as alteraçôes nas práticas mágico-terapêuticas empregadas pelos Guarani, em decorrência do projeto jesuitico de civilização e de conversão que previa a concentração dos indígenas em reduçães e a normatização de suas manifestaçôes rituais e religiosas.

Palavras-chave: Reduçôes jesuiticas, Enfermidade, Cura.

\section{Abstract}

This article has the main objective to introduce the alterations in the Guaranis magic- therapeutic practices, resulting of Jesuit's converting and civilization project, which demanded the concentration of the Indians in mission settlements and the regulation of ritual and devotional expressions.

Keywords: Mission settlements, Illness, Cure.

(recebido em agosto de 2004 e aprovado em janeiro de 2005) 